\title{
Exploring the Nature and Consequences of a Fragmented Activity: The Example of Foremen Managing Operations in an Inland Port
}

\author{
Christophe Mundutéguy* \\ Production Systems, Logistics, Transport, Organisation and Work Research Unit - Université Paris-Est - French \\ Institute of Science and Technology for Transport, Development and Networks, \\ UPE - IFSTTAR - SPLOTT, Descartes 2 - 2, rue de la Butte Verte, F-93166 Noisy-le-Grand Cedex, France.
}

\begin{abstract}
A river container terminal concentrates many of the constraints encountered by different transport modes (road, rail, and waterways) involved in the delivery of merchandises. For the operators in charge of handling operations during peaks of activity, this configuration yields significant difficulties when performing planning, scheduling and dispatching tasks.

The research conducted at the second French river port unravels the mechanisms involved in the management of these dynamic environments. Following a series of interviews and preliminary observations, we conducted systematic observations of the foremen's work. These middle managers are located at the juncture of management and production. The data was completed with additional interviews for the purpose of cross-checking the validity of the results.

The results point to the extreme variability of situations and the high exposure to uncertainty inherent in the transport business. Beyond the tasks of loading and unloading, completed by checks and other operations, container handling consists in trying to absorb, or at least reduce the effects of the combination of constraints in the delivery of merchandises and to ensure greater flow of traffic in the network node. The results also highlight organizational compromises through the permanent adjustment of the means of production in the scheduling and dispatching activities.
\end{abstract}

Keywords: Handling, container, multimodal platform, dynamical environment, scheduling, interrupted activity.

\section{Introduction}

This research is part of a multidisciplinary project (economics, ergonomics, geography, political science and sociology) which seeks to inform the state of river goods transport in metropolitan France and to identify the conditions of its development. This paper presents the preliminary results from the ergonomics contribution. Based on the analysis of the current situation, it examines the consequences of increased traffic on the organisation or production and on the working conditions of materials handling operators of an inland port.

To this end, we chose to focus on routine situations in which there is a significant workload and a strong exposure to hazards (delays, equipment failures, incidents, etc.). Next to various operations (loading, unloading, shipping, etc.) conducted in ports which are all potential sources of malfunctioning, the phase during which a change of transport mode occurs is particularly exposed to hazard. However, high levels of competition, temporal constraints and the risk of accumulating delays make it necessary to fix situations in the shortest possible timeframes to ensure that the most satisfactory deadlines are maintained.

Through an analysis focusing on activity, this paper seeks to shed light on the range of compromises, trade-offs as well as on individual and collective adjustments which play a key role in shaping the sociotechnical system.

\section{Theory}

A port is a multimodal platform from which containers are dispatched via road, rail or waterways. Like any dynamic environment, it changes independently of any action by one or several human operators involved in the process [9]. Its management is largely

*Corresponding author. E-mail: christophe.munduteguy@ifsttar.fr. 
determined by the scope of the field under supervision which can be explored from a causal, temporal or spatial perspective. The intrinsic properties of dynamic environments include amongst others [2, 4]: the continuous or discontinuous aspect of variables, the level of stability of the process, the system's degree of openness, and the level of mediation between the environment and the supervisor. The activities of a port thus present the characteristics of a discontinuous process with a wide range of volumes to be handled. Time management is thus a crucial aspect. This is determined both by the speed at which the process changes, the coexistence of sub-systems with different dynamics and cycles found in the functioning of equipment or external determinants. The multimodal dimension (water, rail, road) combined with environmental intricacies lead to the coexistence of dynamics in a port, the temporalities and constraints of which cannot always be controlled.

The fact that the necessary information is not always easily accessible makes these tasks all the more difficult to perform. ${ }^{1}$ Indeed, the scope of the field determines the accessibility of the process which relates to the distance between the operator and the information he requires to act, as well as the proximity of control which corresponds to the operator's ability to take action more or less directly. In the present case, the operators have very limited power to take action. Since they cannot exert any influence on the flow of goods, their decisions are almost entirely circumscribed to the handling operations within the inland terminal itself. The dynamics of the open environment to which a port belongs, means that within the planning horizon, the data is not entirely known beforehand. Some tasks, such as the processing of trains and barges are already planned, but others, such as the processing of the trucks, add on progressively. The network organisation of multimodal platforms linked to each other by regular lines results in high levels of interdependency. It is therefore necessary to synchronise $\mathrm{TEU}^{2}$ transportation towards the port and to coordinate their various shifts within the port, and this in spite of the fact that, as already mentioned, anticipating is rather difficult. The objective is therefore to schedule without having a clear vision of

\footnotetext{
${ }^{1}$ The type of container, the nature of its content (whether dangerous or not, precious or not, etc.), its origin, intermediary or final destinations, departure or arrival time are far from being systematically known given the very high number of actors involved in the logistics chain and the secondary position of the river port.

${ }^{2}$ TEU: Twenty-foot equivalent unit, a measure used for capacity in container transportation.
}

the planning horizon. This is done in a dynamic fashion as and when new tasks are being assigned while following the planning and or/production objectives [5]. This approach allows the scheduling to remain fluid as it can be re-organised according to the incoming volume of containers to be handled or in response to new incidents or events.

The scope of the field under supervision requires that the organisation and control of production be allocated to various members of the team. The distribution process occurs according to a hierarchical planning of production [1] where we usually make a distinction between goods flow control and production unit control. The goods flow control level also coordinates the various underlying production units. In this hierarchical production planning, McKay and Wiers [7] suggested to make a distinction three levels of decisions: planning, scheduling and dispatching, on the basis of three dimensions previously mentioned:

- $\quad$ Distinct time horizons and time pressure: scheduling and dispatching are in real time with high time pressure whereas planning is used to track daily issues, prepare weekly summaries, monthly plans, yearly plans and so forth.

- Distinct availability of information: planning ensures much more information regarding demand than the lower production control. Planning benefits from personal contacts not available in the scheduling and dispatching contexts.

- Distinct level of dependencies: if the planning impacts on scheduling and dispatching, this function can remain relatively isolated from other functions. Scheduling "tracks any resource and material issue change in capability or capacity that can result in significant constraint changes that are not easy handled by dispatching.

Whilst the authors point out that in most situations, it is difficult to specify at "which point precisely the planning task ends and the scheduling task begins", based on the task analysis from Action science and ethnographic methods combined, according to two attributes: input drivers (expectations for the planner, forecasting for the scheduler and reality for the dispatcher) and output representations of the task (volumes in buckets for the planner and real time for the scheduler and the dispatcher).

When circulating, goods are highly exposed to hazards. However, the high levels of competition in the transport sector require that the highest possible 
fluidity be maintained to ease the flow of goods within multimodal platforms. To explain the strategies that make this result possible, we make the hypothesis that the management of the port's platform amounts to a dynamic scheduling activity dispatched between several operators on the production chain. The dispatching task must help reduce the complexity of the process, notably through the management of its various temporalities. Although the existing literature discusses the dynamic dimension of planning, little is said about the mechanisms that allow the capacities to be adjusted to needs of the situation according to the dynamics of the situation. Grounding our analysis within the framework of Activity Theory $[3,6]$ which pays particular attention on the definition of activity via the subject (individual or group), the activity object, actions and operations, we make the hypothesis that scheduling is the result of compromises in the goals of the subject's activity which take the shape of trade-offs. We offer to explore some of the rules that underpin these trade-offs. Eventually, the hypothesis we make is that managing this type of dynamic environment amounts to a permanent compromise between the goals of the action that determines the planning of the agent(s) in charge of supervising the platform and adjusting the goals according to the dynamics of the situation.

\section{Methodology}

This research was conducted in three stages. An exploratory stage looking at the overall organisation of container terminals and the global activity related to the load transfer between different modes of transport on this multimodal platform. Based on exploratory in-depth interviews with several actors ${ }^{3}$ involved in the production process and on direct observation, this stage helped underline the key role of the foreman. The foreman finds himself at the centre of the production system, i.e. at the juncture between the direction and management of client accounts on the one hand, and the production undertaken by the operators in charge of transport on the other. This means that the smooth running of operations is very dependant on his activity. This stage also helped identify the cyclical properties of the activity. Two days of the week (Tuesdays and Fridays) are marked by significant peaks in activity. This is because of Strasburg's geographical location on the Rhine and

\footnotetext{
${ }^{3}$ The Head of Strategy, the Terminal and Business Operations Manager, the Operations Manager, one of the four foremen and one of the eight team managers.
}

its distance to Amsterdam and Antwerp, the two main maritime ports which it is connected to. Sea ships tend to arrive in those two ports on specific days. In order to explore the individual and collective regulation mechanisms, we made our period of observation coincide with one of these days of the week, i.e. a Tuesday. The observation conducted on the previous day was used to examine the stage of preparation and that conducted on the following day, the potential stage of recovery.

We conducted the data collection in two stages which focused on the individual and collective management of the multimodal platform at the level of its operational decision-making centre. The dataset was based on audio, video and photographic recordings of interactions between the different agents involved in the process which we completed with written notes. It looked at the circulation of information between people and objects, the media used, the decisions taken regarding actions, the negotiation between various operators, and the resulting allocation of tasks. Explanatory interviews were conducted in itinere or ex post with those actors identified as being in charge of scheduling and dispatching within the production process. Following the transcription of audio and video recordings, the data analysis was conducted around a series of key topics and data synchronisation so as to put them into context through an activity diary. The objective was to recover some of the dynamics of the activity combined with that of the environment.

\section{Fieldwork}

The Autonomous Port of Strasbourg has three operations sites including two container terminals which boast an operational multimodal platform (rail, road, water) on which this research was conducted. It is located on the shores of the Rhine, which is Europe's major commercial river with regard to container transport with 300 million tons, that is $2 / 3$ of western Europe's river traffic.

\subsection{Staff}

Three operators intervene in the operations' hierarchical planning: the Operations Manager, who is in charge of planning teamwork and technical decisions, the Terminal and Business Operations manager, in charge of coordinating requests from customers and the foremen who implement managerial decisions on each of the terminals. The two former share some of 
the planning functions while the foremen share a scheduling function with the Operations Manager and are the sole people in charge of dispatching on each of the sites.

The organisation of a terminal relies on three weekly teams, as follows: morning (5.45 am to 1.30 $\mathrm{pm})$ and afternoon (1.15 pm to $9 \mathrm{pm})$ teams: one team manager, 4 handling operators (forklift truck and/or portico operators), one train manager (in charge of controlling operations on the train) and one gateman (in charge of controlling the containers arrived by truck).

If the teams are stable, the operators can freely move from one team to another as they are being posted onto another site or another time slot than the one initially planned. The organisation of work thus displays significant flexibility [8]. Staff is regularly asked to perform extra working hours as long as the legal limit that would require the creation of an additional team is not exceeded. For example, the members of the morning or afternoon team may be asked to work during the evening or at week-ends. The handling operators increasingly need to be able to drive the entire range of vehicles to be able to intervene on all types of loads.

\subsection{Technical resources}

To conduct the transfer of loading operations, at the time of our observations, the terminal was equipped with:

- 2 container cranes ${ }^{4}$ with front and rear booms, allowing four levels of storage under the crane.

- 3 reach stackers ${ }^{5}$ allowing to load a train only on one track and two which can load on two-tracks as required by the spatial configuration of the platform (which has two adjoining railroads)

- Communication tools (IT management system, radio communication system, landline telephones, and mobile telephones for the foremen).

\subsection{Technical resources}

The dynamics of the platform are determined both by incoming and outgoing containers and the various operations carried out by the handling agents. Each

\footnotetext{
${ }^{4}$ Container crane (also Container handling gantry crane, shipto-shore crane): Mobile crane for loading and unloading intermodal containers from container ships

${ }^{5}$ Reach stacker: Mobile high-powered truck with a telescopic lifting arm of up to $35 \mathrm{t}$ lifting capability for bottom lift of swap bodies.
}

mode of transport is related to a process determined by pre-arranged stages which are more or less performed or supervised by the foreman. These are briefly presented in Figure 1 to help understand all the tasks that are being entrusted to the foreman.

Next to these tasks, the foreman also deals with the containers on the platform. Depending on the requirements, he stacks them into blocs according to category ${ }^{6}$ but in an indistinct fashion from the point of view of the maritime companies. In case there is a booking, he can also store them to allow for a regrouping of containers from a same company.

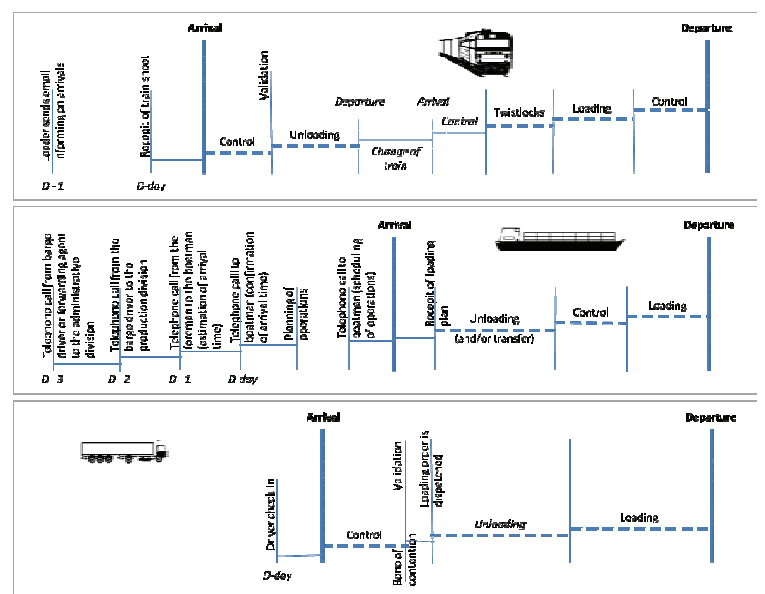

Fig. 1: The various stages in the handling of containers according to the mode of transport used

\section{Case study}

The results concern mainly the first stage of data collection. However, the second stage which took place six months later displays similar features.

\subsection{The determinants of variability}

The multimodal platform combines the full range of constraints experienced by the modes of transport that feed it. This characteristic determines a significant part of the variabilities in working conditions. Although heavy goods vehicles follow cycles linked to their rotations, the amount of units and arrival times are unpredictable.

Trains offer a number of units to be handled that is known in advance and arrival times that are relatively

\footnotetext{
${ }^{6}$ The containers vary according to various features: size $(20,30$ or 40 feet), standard or high cube, category, food or non-food, empty or full, etc.
} 
predictable as long as they remain within their path. ${ }^{7}$ If this is not the case, it can have a 24,48 or even 72 hours delay necessary to enter a new path. This was the case during our second stage of observation with a train circulating between Le Havre and Strasburg. It is therefore absolutely imperative to remain within the time schedule and to stick stringently to the departure time.

Whilst the arrival of the boats is predictable, strong variations may still occur (in hours or in days) due to operations in the other ports or to travel conditions. Moreover, the containers missing from the loading schedule may have to be unloaded to make up for the operations which were not carried out in the previous port. Next to the red tape they generate, these unplanned operations must be carried out in the shortest possible time.

The other source of variability concerns the equipment which is heavily used. The quantity and the requirements of production do not always allow to systematically conduct preventive maintenance operations. The hazards affecting equipment are also usual. When operations require specific equipment (i.e. container crane for boats, reach stackers equipped with stabilizers for a two-lane loading for train), the foreman must quickly work out a new solution in order not to upset the flow (moving boat, changing the lane for the train, delaying the dispatching...).

All the delays that affect barges and trains entail moving operations into the schedule or to other teams. The supervision of the multimodal platform therefore requires a revision of the scheduling as well as regular improvements. This is particularly necessary given that, for financial reasons, the production system remains unadjusted to activity peaks. ${ }^{8}$ This point does not only apply to the case study site. While investments remain important overall, the competitive dimension of the transport sector means that the margins on operations are relatively low.

5.2 The foreman of a multimodal platform: a 'scheduler-dispatcher' with a fragmented activity

\footnotetext{
${ }^{7}$ Train path: Infrastructure capacity needed to run a train between two places over a given time period, i.e. the period during which a given infrastructure is allocated to the circulation of a train between two positions on the rail network.

8 " (...) If you want to reduce contingency, you have various options. You can either match the level of resources to fit peak times, in terms of staff and equipment, but that's no good. So in any case, they're not adjusted to peak times. This means that there are times when I'm a little bit overwhelmed (...)". Head of Strategy, 07 June 2010, p.5.
}

One or several days before the containers arrive, the foreman collects the necessary information for the planning of operations, teams and material resources. This is done in liaison with the operations' manager and the administrative staff headed by the terminal and commercial operations' manager. Another activity adds onto this main task, namely the scheduling and dispatching of means which is contingent upon the changing situation.

As illustrated in the activity diary (Figure 2), the activity of the foreman is very fragmented. The object of his activity moves between the supervision of the agents handling the various modes of transport (almost exclusively trains and barges), the management of the containers on the platform (blocs, stocks, stacking, and the management of the resources (human, technical, spatial and temporal) that are both necessary and available to perform the required change of mode or storage.

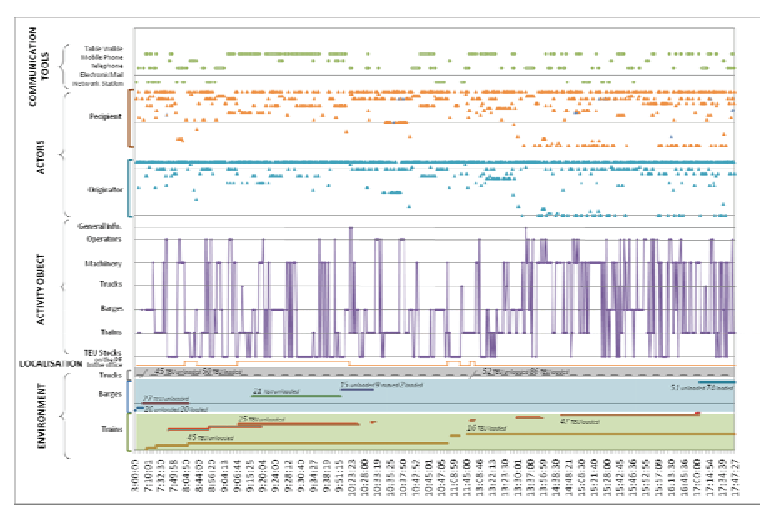

Fig. 2: Diary of the overall activity

\begin{tabular}{lccccccc}
\hline Time & TEU & Tra. & B & T & Mach. & Op. & Und. \\
\hline AM & $2: 16$ & $1: 12$ & $0: 48$ & $0: 03$ & $0: 16$ & $0: 06$ & $0: 19$ \\
PM & $0: 16$ & $1: 08$ & $0: 23$ & $0: 03$ & $2: 37$ & $0: 22$ & $0: 33$ \\
\hline Total & $2: 33$ & $2: 20$ & $1: 11$ & $0: 06$ & $2: 52$ & $0: 28$ & $0: 52$ \\
$\begin{array}{l}\text { Tra.: Train; b : Barges ; }: \text { Trucks ; Mach. : Machinery; Op; : Operators ; Und. : Unde- } \\
\text { termined }\end{array}$
\end{tabular}

Tab. 1: distribution of the foreman's activity time devoted to the various activity objects for the morning and afternoon

The morning tends to be devoted to the management of containers, to their scheduling and stacking on the platform $(45.5 \%$ of the time compared to an average of $23.6 \%$ for the whole day) on one hand, and to the train on the other $(23.9 \%$ of the time compared to an average of $21.6 \%$ for the whole day) (see Table 1). In the afternoon, the object of the foreman's activity is largely devoted to the management of the equipment and the train. With regard to artefacts, the 
foreman's interventions do not just apply to their allocation. He initiates some of the maintenance planning, controls their performance and also takes part in their development. With regard to this aspect, on the day the activity diary was recorded, the foreman spent much of the afternoon developing the information system interacting with a service provider. This specific point helps explain the importance of the time devoted to this task (Table 1). The allocation of resources devoted to its handling keeps the foreman less busy in terms of hourly volume. But the activity of the foreman is not limited to the control of the operations performed on the multimodal platform. Depending on the workload and the level of availability of the handling agents, he may have to leave his office to perform one of the operations required to switch mode (control or cleaning of the containers, checks at the arrival of the train, fitting of twist locks, etc.) while remaining in contact with the different actors of the network via radio or mobile telephone as shown in the activity diary.

\subsection{Scheduling: an activity between planning and opportunism}

If all the foreman's activity objects are taken together according to time slots (Figure 4), the ways in which the change of objects occurs becomes clearer. The weight of each of the objects displays an internal dynamic which is specific to the time of the day. At the start of the morning, as long as the train is not yet arrived on the platform, the foreman allocates the resources to the handling of the barges that have arrived at night or in the morning on the one hand, and to the unloaded containers on the platform on the other (Figures 3 and 4). Once the incoming train has been checked by the train or team manager, he reallocates the means to its unloading "to make room for the loading". If the tasks being performed allow it, while he waits for the twistlocks ${ }^{9}$ to be fitted, the foreman asks the forklift truck drivers to place the containers to be loaded on the train in front of their future position. This strategy answers three objectives: bringing the operations related to the train forward as much as possible, freeing space in the stocks or blocs, and reducing the number of handling operations. As shown in the activity diary, there are constantly operations being performed on the train

\footnotetext{
${ }^{9}$ Twistlocks is sued for securing shipping containers The primary uses are for locking a container into place on container ship, semi-trailer truck or railway container train and for lifting of the containers by container cranes and sidelifters.
}

throughout the day, while they tend to considerably diminish in the afternoon with regard to containers which are more likely to leave than enter the platform. The management of the stocks and space seeks to reduce the entropy of the platform. With it being uncluttered, this objective is less important. This activity is the final object of the day when the situation is relatively stabilised. Regarding the other modes, the trucks hardly require any intervention from the foreman $(0.89 \%$ of his time throughout the day). The gateman and the coach drivers only call upon him if there is a bone of contention related to a damaged container. The barges are managed as and when they arrive, according to the level of involvement on the two main objects (containers and trains).

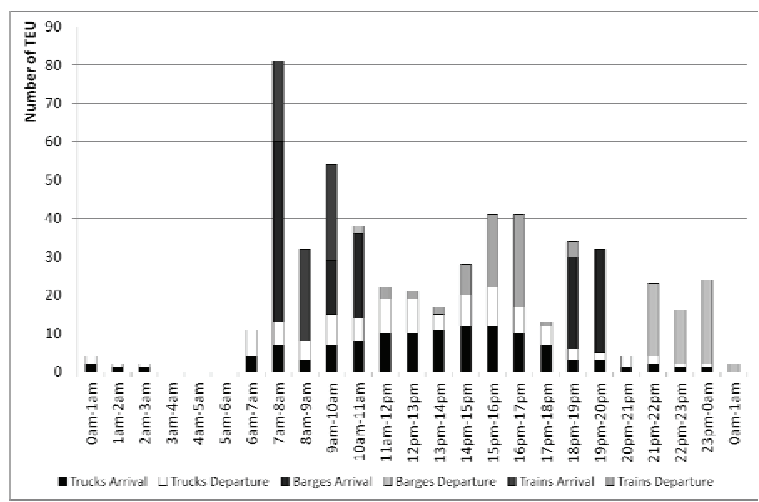

Fig. 3: Number of TEU handled for the various modes of transport according to time slots

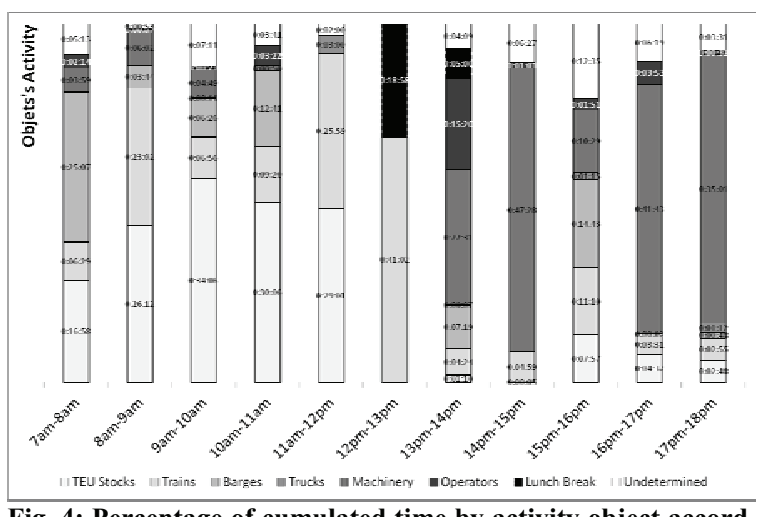

Fig. 4: Percentage of cumulated time by activity object according to time slots

\subsection{Scheduling: a distributive activity}

The time slots during which one sees the most frequent changes of objects are 9 am to $11 \mathrm{am}, 1$ to $2 \mathrm{pm}$, 3 to $4 \mathrm{pm}$ (Figure 5). If the first slots corresponds to the containers' arrival peaks by barge or train as already mentioned, the second slot is the one taking 
place just after the lunch break when departures are more important than arrivals as this is the case during the third slot. Moreover, the majority of these arrivals applies to trucks which do not require any intervention from the foreman. The change of objects is not entirely due to the TEU volume to be handled and to the diversity of modes. Does the foreman's activity present its own dynamics, partly independent of that of the environment?

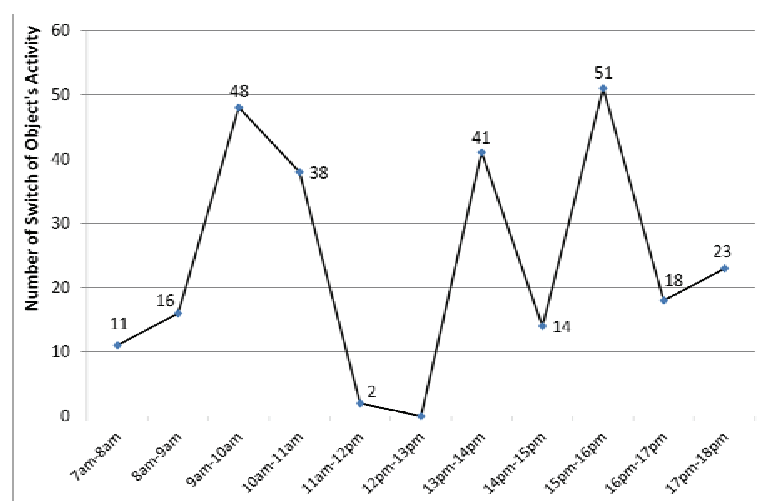

Fig. 5: dynamic of changes in the objects of activity according to time slots

Around twenty actors were involved in the diary, either as originators or as recipients of the action already underlined the central role of the foreman in the production system. The fragmentation of the foreman's activity is both a cause and a consequence of permanent adjustments meant to correct or reduce the effects of uncertainty. It also results from the frequent and regular requests directed at him as a (recipient) or initiated by him (originator).

While he mainly initiates the changes of objects during the morning, it is striking that in the afternoon, it is increasingly related to the intervention of a third party (Figure 6). While keeping the final decision, the foreman partially delegates the control of the situation and the scheduling of the operations when he is involved in a peripheral task such a developing a production tool (Figure 2). Hence, at the beginning of the afternoon, the changes of objects which remain largely related to the scheduling of operations (Figure 4) are to a great extent or similarly related to the intervention of a third party. ${ }^{10}$ The foreman intentionally discharges this scheduling task during quieter time slots, when there are less train departures than

\footnotetext{
${ }^{10}$ Direct requests are those explicitly directed at the foreman. Indirect requests are those that refer to a third party's actions or comments which are caught by the foreman without him being the recipient. The direct and indirect requests selected systematically lead to a change of object in the foreman's activity.
}

arrivals and when the departure time is still quite distant. However, between $3 \mathrm{pm}$ and $4 \mathrm{pm}$ which is the third peak with regard to changes in the object of activity, he switches back to a control mode. This switch back mode reflects the fact that he anticipates the train departures $(6.08 \mathrm{pm}$ and $6.50 \mathrm{pm})$ and the end of his daily duties $(5.55 \mathrm{pm})$. Without necessarily waiting for the ongoing operations to be over, before leaving the workplace, the foreman makes sure that the situation is stabilised with regard to the management of space (stacking of containers) and time (operations of modal transfer).

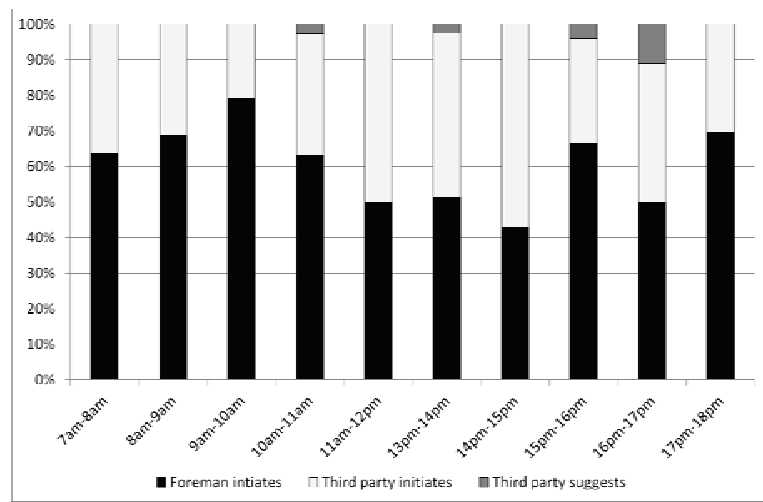

Figure 6: Share of the foreman's and other platform agents' time in the change of activity objects

\section{Conclusion}

The fragmentation of the foreman's activity is the combined result of the planning of operations and the requirements of the situation (expected arrival and departure times) and the potential emergence of hazards regarding the various mobiles, containers, equipment or staff. This process guides the scheduling of operations and the dispatching of resources. Scheduling thus amounts to a permanent adjustment of resources and means of production to changing situation and constraints.

Rather than following a strict rule which would consist in systematically resorting to the same mode of transport - namely the train which features strong constraints - over the others, the foreman makes a range of trade-offs according to the requirements of the situation and to temporal, spatial, technical and human resources at his disposal. These resources are hence generally managed selectively throughout the day. They enable him to reach the most satisfactory adjustment between the requirements of a situation that is unpredictable because of it is determined by 
the dynamics of the situation (moving between foreseen and unforeseen events) and the availability of technical resources (predictable and unpredictable in certain cases). The latter do not match the range of planned resources but actual resources which include staff leaves, dysfunctions or other equipment failures.

The management of resources is an odd dimension of the foreman's activity. Indeed, the important strain on staff and equipment during peaks of activity creates tensions which the foreman tries to reduce during off-peak periods [8]. This approach to resource management is particularly crucial given the importance of anticipating the consequences of certain dysfunctions and monitoring performance. These tasks are partially divided between the foreman and the other sectors of the platform. During three consecutive days of observation, we noted that the forklift truck operators and the team manager were transferring information to the foreman on the state of the equipment likely to break down and to impede the adjustment of operations. On several occasions, this resulted in negotiations between these staff and the foreman to plan alternative operations. Another form of scheduling distribution can be seen through the significant autonomy enjoyed by the forklift truck operators in the handling of their vehicles. Finally, the fact that the foreman leaves the platform before the completion of operations, and notably before the train has left, underlines his willingness to discharge some of his duties. This is not fortuitous. While ensuring the resources allow the operations to be completed within the given deadlines, the foreman strengthens his team and his position by expressing his trust.

Finally, our results highlight that two major determinants of the situation, i.e. time and space can move from the status of resources to that of constraints and inversely. At the start of the day, the most important constraint is related to space. To ease the flow, the foreman must reduce entropy. Given the operations to be performed, he enjoys a comfortable amount of time. When space and time are combined into resources, while keeping the final check, the foreman discharges some of his scheduling duties to the other actors.

The time variable switches from being a resource (i.e. time available to perform operations) to being a constraint as the deadlines near certain thresholds (i.e. time to handled a boat or a truck which cannot be exceeded and departure time of the train). A deadline is crucial in the scheduling of operations on the platform given that it cannot be compressed: the time of departure of the train(s) set by the hourly tracks.
When time turns into a constraint, the foreman must reallocate most of the resources to complete the loading of the train.

The results underline that it is not only necessary to take into account the status of variables but also to maintain the distributed feature of the control and scheduling tasks when developing tools to facilitate scheduling activities. The foreman fulfils the task of a 'scheduler-dispatcher' but on occasions, he may also cover for certain handling operators or for the train manager. If he fails to take into account this fragmentation of activity, the foreman may find himself cut from the team. If he can help reduce the workload of one of his agents by taking on some of his tasks, he can also discharge some of his own workload, as we have shown through the management of artefacts.

\section{Acknowledgments}

This research was one part of the FLUIDE project supported by French National Research Agency.

\section{References}

[1] JWM. Bertrand, JC. Wortmann, J. Wijngaard, Production Control: a Structured and Design Oriented Approach, New York: Elsevier, 1990.

[2] J-M. Cellier, V. De Keyser, C. Valot, Expertise in dynamic environments, Ergonomics, 40:1 (1997), 28-50.

[3] Y. Engeström, R. Miettinen, R.-L. Punamaki, Perspectives on Activity Theory, Cambridge: University Press., 2004

[4] J-M. Hoc, Some dimensions of a cognitive typology of process control situations, Ergonomics, 36:11 (1993), 1445-1455.

[5] J.-M. Hoc, N. Mebarki, J. Cegarra, L'assistance à l'opérateur humain pour l'ordonnancement dans les ateliers manufacturiers [Assisting human operators in the scheduling in production workshops], Le Travail Humain, 67 (2004), 181-208.

[6] L. Leontiev, Activity, Consciousness, and Personality, Hillsdale: Prentice-Hall, 1984.

[7] K.N. MacKay, V.C.S. Wiers, Planning, scheduling and dispatching tasks in production control, Cognition Technology and Work, 5 (2003), 82-93.

[8] 14/ C. Mundutéguy, Système sociotechnique sous tension: quelles conséquences pour les agents de manutention? Le cas d'un terminal à conteneur de port intérieur [Socio-technical system under tension: which consequences for handling agents? The case of a container terminal in an inland port], GECOPE Conference, International Days on «Governance and Port Communities in Europe », Nantes, 2011.

[9] R. Samurçay, J-M. Hoc, De l'analyse du travail à la spécification d'aides à la décision dans les environnements dynamiques, Psychologie Française, 33 (1989),187-196. 